\title{
Identification and characterization of factors associated with short stature and pre-shortness in Chinese preschool-aged children
}

\author{
Min Yang ${ }^{1,3}$, Xiangling Deng ${ }^{1,3}$, Shunan Wang ${ }^{1,3}$, Bo Zhou ${ }^{1,3}$, Wenquan Niu ${ }^{4}$ and Zhixin Zhang ${ }^{2,3}$ \\ ${ }^{1}$ Graduate School, Beijing University of Chinese Medicine, Beijing, China \\ IInternational Medical Services, China-Japan Friendship Hospital, Beijing, China \\ ${ }^{3}$ Department of Pediatrics, China-Japan Friendship Hospital, Beijing, China \\ ${ }^{4}$ Institute of Clinical Medical Sciences, China-Japan Friendship Hospital, Beijing, China \\ Correspondence should be addressed to W Niu or Z Zhang: niuwenquan_shcn@163.com or zhangzhixin032@163.com
}

\begin{abstract}
Objectives: We aimed to identify and characterize potential factors, both individually and jointly as a nomogram, associated with short stature and pre-shortness in Chinese preschool-aged children.

Methods: Total of 9501 children aged 3-6 years were recruited from 30 kindergartens in Beijing and Tangshan from September to December 2020 using a stratified random sampling method. Effect-size estimates are expressed as odds ratio (OR) and $95 \% \mathrm{Cl}$. Results: The prevalence of short stature and pre-shortness in preschool-aged children was $3.9 \%(n=375)$ and $13.1 \%(n=1616)$, respectively. Factors simultaneously associated with the significant risk for short stature, pre-shortness and both included BMI, paternal height, maternal height, birth weight, birth height, latter birth order $(\geq 2)$ and less parental patience to children. Besides, breastfeeding duration ( $\geq 12$ months) was exclusively associated with pre-shortness (OR, $95 \% \mathrm{Cl}, P: 1.16,1.01$ to $1.33,0.037)$, and childhood obesity with both short stature $(3.45,2.62$ to $4.54,<0.001)$ and short stature/ pre-shortness $(1.37,1.15$ to $1.64,<0.001)$. Modeling of significant factors in nomograms had descent prediction accuracies, with the C-index being $77.0,70.1$ and $71.2 \%$ for short stature, pre-shortness and both, respectively (all $P<0.001$ ).

Conclusions: Our findings indicate the joint contribution of inherited characteristics, nutrition status from the uterus to childhood, and family psychological environment to short stature and pre-shortness in Chinese preschool-aged children. Further validation in other independent groups is warranted.
\end{abstract}

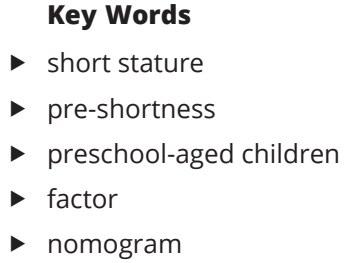

Endocrine Connections (2021) 10, 607-619

\section{Introduction}

Short stature is increasingly recognized as a worldwide public health concern, and it affects about $3 \%$ to $11 \%$ of children worldwide $(1,2,3,4)$. In China, the prevalence of short stature was estimated to be $3.7 \%$ among children from 7 to 18 years of age (4). Short stature is commonly seen in pediatric endocrinology units in routine clinical practice (5). Considering the fact that immediate and effective interventions can improve final adult height, early identification of factors that can predict pre-shortness or short stature in children is crucial to implement timely interventions that may reduce or prevent the occurrence of short stature in adulthood.

The detrimental consequences of short stature have drawn special attention due to its underlying physical and psychosocial impairments from childhood to adulthood, such as cardiometabolic diseases, diabetes and

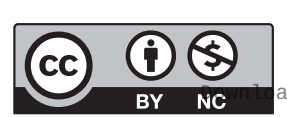


psychological functioning problems $(6,7,8,9)$. In clinical practice, pre-shortness is often the major reason for medical appointments, as more and more parents are anxious that children with shorter body height may pursue less higher education, have less employment opportunities, and even have problems with heterosexual relationships $(10,11,12)$. Further from clinical aspects, childhood pre-shortness may be a harbinger of short stature in adulthood due to the multifactorial and complex contributions to height gain process. Our recent study indicated that pre-shortness was inclined to be affected by modifiable factors than short stature (13), underscoring the importance of prevention and control at the stage of pre-shortness. Hence, it is of public health and clinical importance to identify and characterize factors associated with short stature and preshortness in children and help obtain satisfied final body height in adulthood.

It is generally believed that human height is a complex trait on which inherited and environmental factors act interactively $(14,15)$. About $20 \%$ of short stature is pathological, and $80 \%$ is idiopathic due to unknown causes (16). Factors associated with less height gain have been extensively evaluated, yet the results are not often reproducible, especially for modifiable factors $(17,18)$. For example, some studies have shown that high BMI was positively associated with short stature and pre-shortness $(13,19)$, whereas others failed to support this claim (20). The reasons for inconsistent results are manifold, possibly due to differences in races or ethnicities, genetic underpinnings, study designs, statistical power, as well as the characteristics of study populations.

To shed some light on the possible reasons and yield more information for future studies, we undertook a largescale, cross-sectional survey in Chinese preschool-aged children from 30 randomly selected kindergartens in Beijing and Tangshan, aiming to identify and characterize potential factors that were significantly associated with short stature and pre-shortness, both individually and jointly as a nomogram prediction model.

\section{Methods}

\section{Study design}

The cross-sectional survey was done in Beijing and Tangshan from September to December 2020. The conduct of this survey was reviewed and approved by the Ethics Committee of China-Japan Friendship Hospital and was in compliance with the principles of the Declaration of
Helsinki. Parents or guardians of all study children have read and signed informed consent forms prior to participation.

\section{Study children}

Study population included preschool-aged children attending junior to senior kindergarten classes at the time of enrollment. Using a stratified cluster random sampling strategy, 4 out of 16 districts in Beijing and 2 out of 7 districts in Tangshan were selected. Within each district, 5 kindergartens were selected, and 30 kindergartens were included finally. Children who are diagnosed to have major illnesses such as chronic kidney disease, hypothyroidism, or congenital heart disease were excluded from the present analysis.

\section{Data collection and quality control}

Self-designed questionnaires were sent to the parents or guardians of study children. From children, surveyed data included sex, region, date of birth, time spent on outdoor activities at workdays and weekends, weekly intake frequency of fast food and night meals, picky eating, birth weight, birth height, gestational age, delivery mode, twins or not, birth order, breastfeeding duration and solid food introduction age. Weight (to the nearest $0.1 \mathrm{~kg}$ ) and height (to the nearest $0.1 \mathrm{~cm}$ ) of children were measured by trained healthcare physicians. From parents, self-reported data on age, height, gestational diabetic mellitus, education, family income, and self-rated patience to children were recorded.

Kindergarten teachers were in charge of sending the electronic questionnaires to the parents or guardians of all participating children. Data were exported from electronic questionnaires to a Microsoft Office Excel ${ }^{\mathrm{TM}}$ spreadsheet and were strictly checked by trained staff. In case of missing or uncertain records, parents were contacted for the sake of clarity.

\section{Definition of short stature and pre-shortness}

Children with height $z$-scores $<-2$ s.D. are defined as short stature according to age- and sex-specific measures under the China criteria (2009) (21). Children with height z-scores between $<-1$ S.D. and $\geq-2$ s.D. are defined as preshortness.

\section{Definition of other characteristics}

For children, BMI was calculated as measured weight divided by height squared $\left(\mathrm{kg} / \mathrm{m}^{2}\right)$. BMI category was

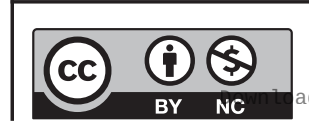

This work is licensed under a Creative Commons Attribution-NonCommercial 4.0 International License. ded from Bioscientifica.com at 04/26/2023 12:01:54PM 


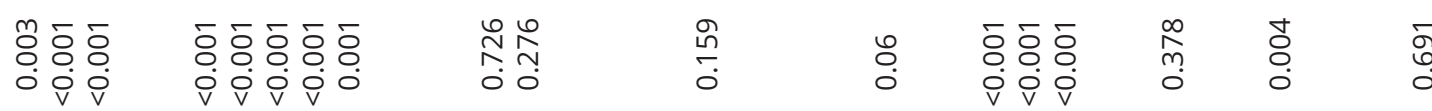

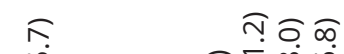

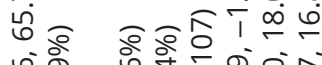
守

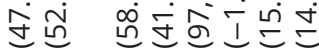

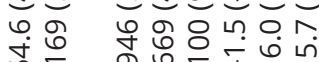

๙๐aำ

웡ํㅇ

웡

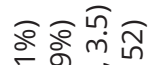

过

in

क ०े ने

넸은

m虽守

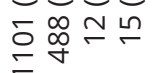

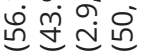

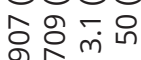

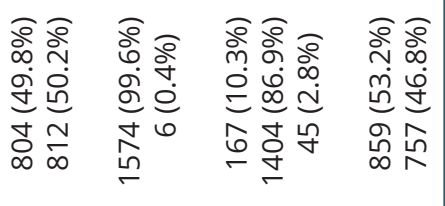

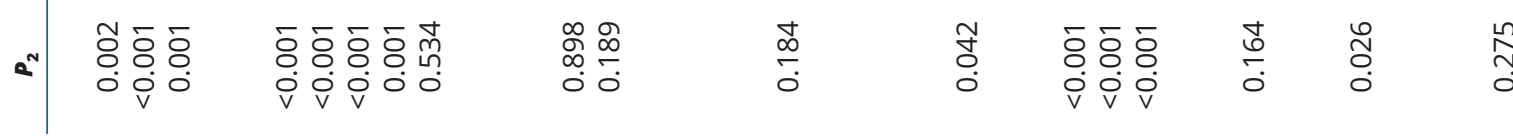

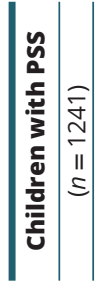

क त़ธิ

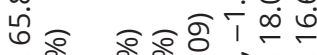

ب़่

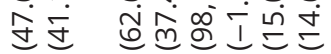

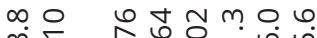

จ욕

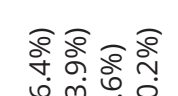

ம்

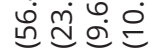

每

융유뉸

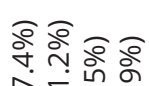
6.

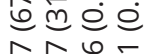

过过

ஓे

वे

वें के के 记

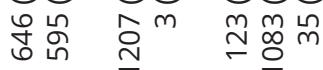

वे กำ in

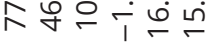

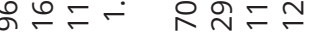

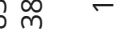

命婴 กำ

$\stackrel{-10}{0}$

क्ष

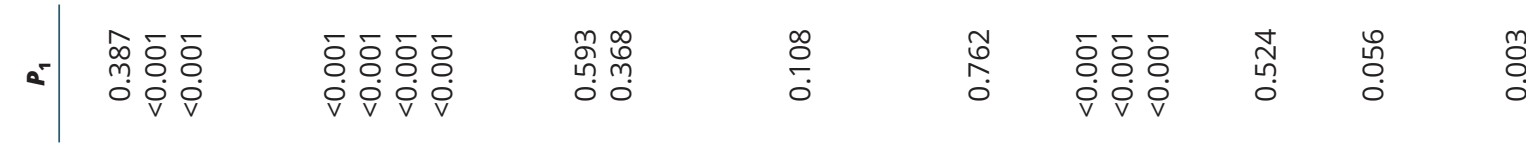

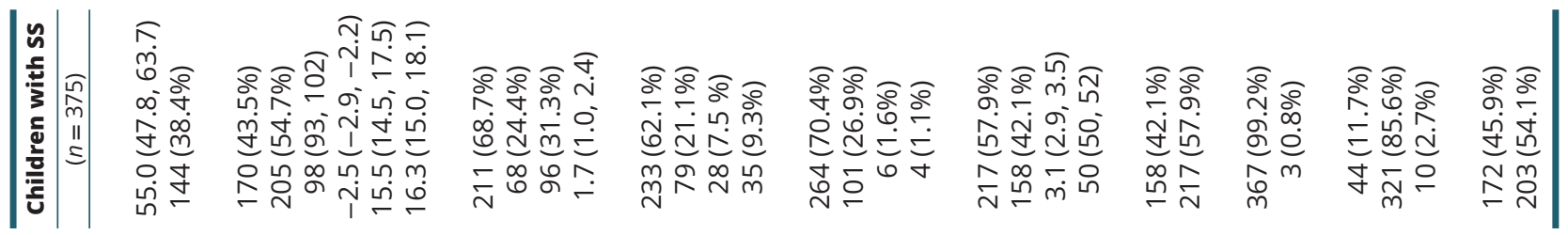

ล.

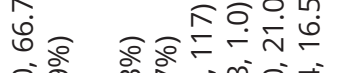

จㅇํำ

में के के

过

ก न

$\infty$ 넨요

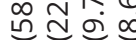

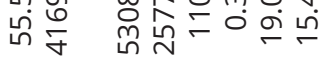

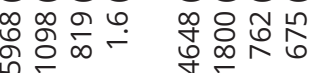

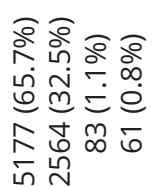

वेल

舟守家

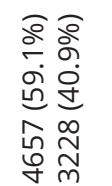

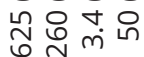

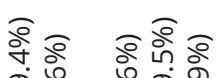

ㅎํำ

बें ஹ

ஸ் (1)

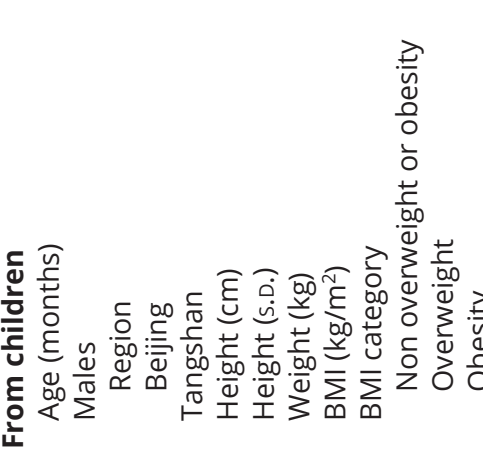
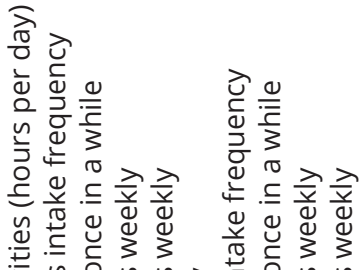

约

언

可

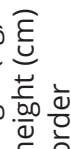

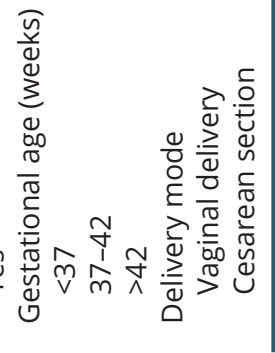




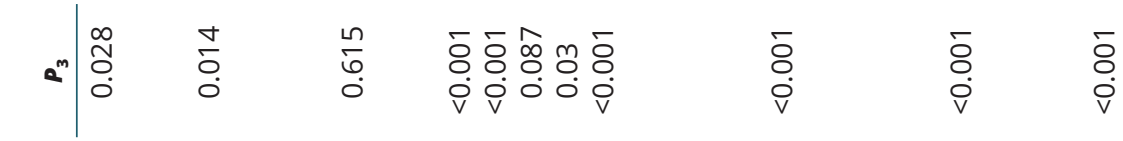

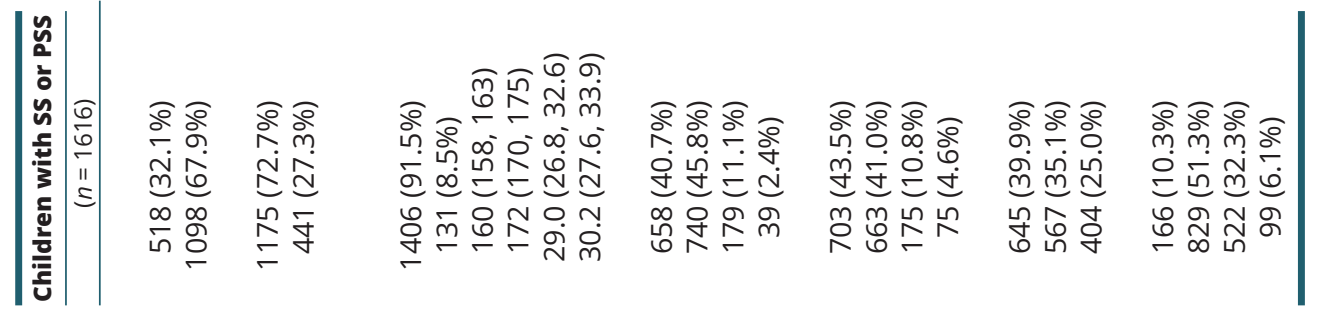

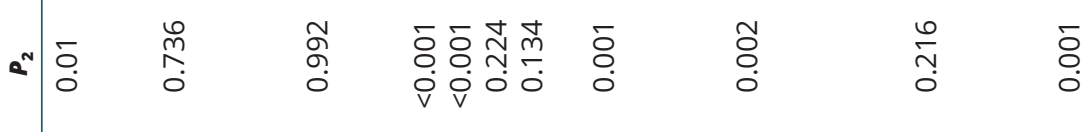

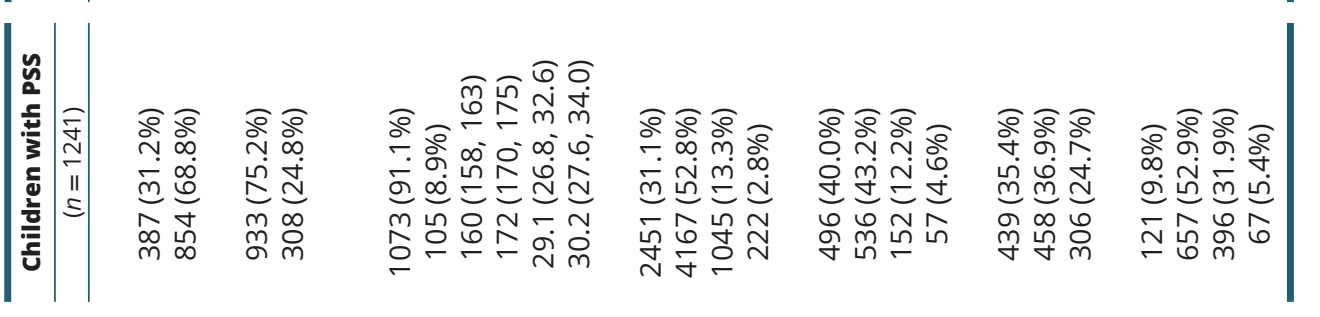

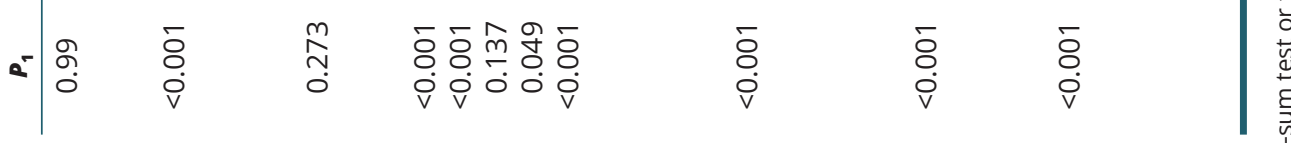

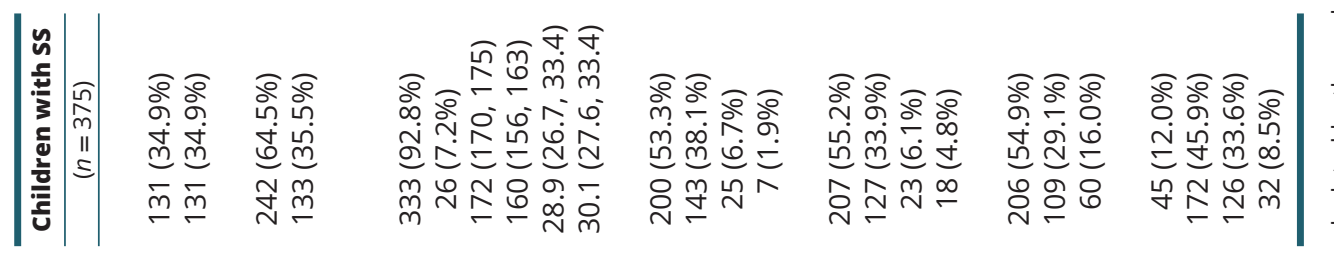

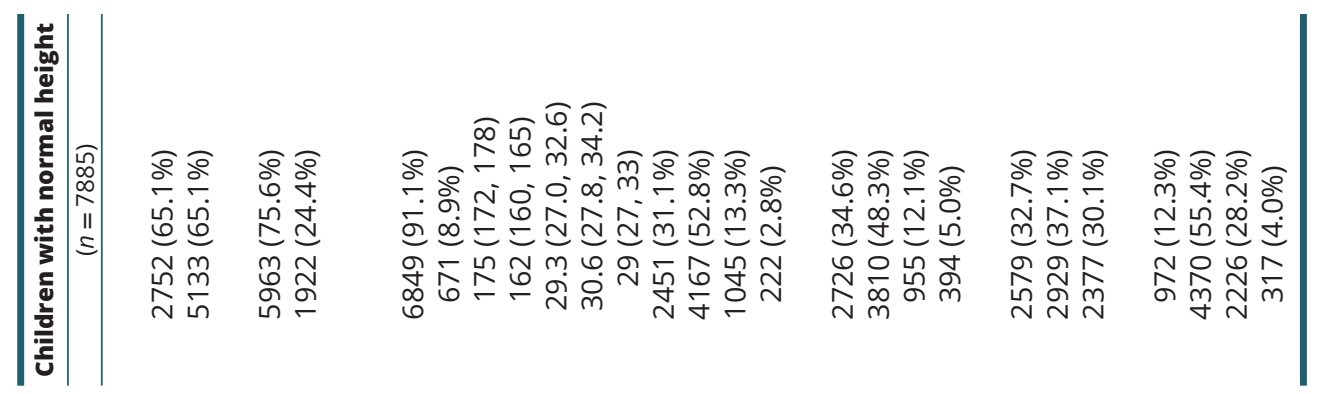

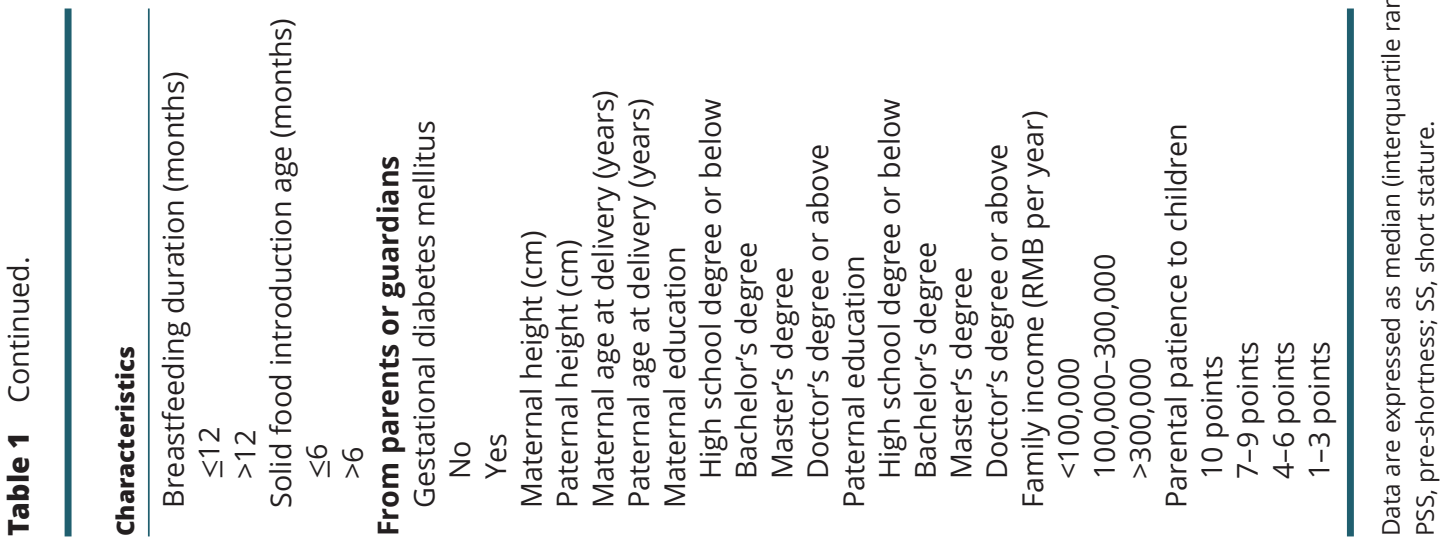


defined as obesity, overweight and non-overweight or obesity according to the China criteria (2009) (22). Time spent on outdoor activities every day was calculated as the sum of time both on workdays $\times 5$ and weekends $\times 2$ divided by 7. Fast food is referred to as food with high energy and low nutrition (e.g. hamburger and french fries), night meal is defined as eating food within $2 \mathrm{~h}$ before bedtime. And weekly intake frequency was consistent with fast food and night meals, which were classified as every day, often (three to five times), occasional (one to two times) or none or once in a while. Picky eating was defined as yes or no. Birth order was grouped into $<2$ and $\geq 2$. Whether twins or not was also recorded. Additionally, gestational age was divided into $<37$ weeks, $37-42$ weeks, and $>42$ weeks. Delivery mode included vaginal delivery and cesarean section. Breastfeeding duration was classified as $<12$ months, and $\geq 12$ months according to the mean value. Solid food introduction age was recorded in months.

For parents or guardians, maternal and paternal height were self-reported. Maternal and paternal age at delivery were calculated as the difference between the date of child's birthdate and parents' birthdate. Maternal gestational diabetes mellitus diagnosed by doctors from second-class or above hospitals were recorded. Education was categorized as doctor's degree or above, master's degree, bachelor's degree, and high school degree or below.
Family income (RMB per year) was categorized as $>300,000$, $100,000-300,000$ or $<100,000$. Parental self-rated patience to children was separated into 10 points, 7-9 points, 4-6 points and 1-3 points. Lower points represented less patience to children in their daily life.

\section{Statistical analyses}

The distributions of continuous variables between two groups were assessed for normality by the use of the skewness and kurtosis test. Skewed continuous variables are expressed as median (interquartile range) and normally distributed variables as mean (S.D.). Categorical variables are expressed as numbers (percentage). Between-group comparisons were implemented by the $t$-test or rank-sum test or $\chi^{2}$ test, where appropriate.

To examine whether there is a possible bias arising from different kindergartens, intraclass correlation coefficient (ICC), which is a statistic that can be used to quantify the degree to which observations within a cluster differ from those between clusters,(18) was calculated.

To identify significant factors associated with childhood short stature and pre-shortness, multivariable linear regression analyses using the Stepwise method were first done. Standardized and unstandardized regression coefficients, as well as $95 \% \mathrm{CI}$ and $P$ value were recorded.

Table 2 Multivariable regression analyses of potential contributing factors on height (s.D.) in preschool-aged children

\begin{tabular}{l}
\hline Variables \\
\hline Age (months) \\
Males \\
Region \\
Children BMI (kg/m²) \\
Maternal height (cm) \\
Paternal height (cm) \\
Birth height (cm) \\
Birth weight (kg) \\
Gestational age (weeks) \\
Gestational diabetes mellitus \\
Birth order \\
Twins \\
Breastfeeding duration (months) \\
Solid food introduction (months) \\
Night meals intake frequency \\
Fast food intake frequency \\
Outdoor activities (hours per day) \\
Picky about food \\
Maternal age at delivery (years) \\
Paternal age at delivery (years) \\
Maternal education \\
Paternal education \\
Family income (RMB per year) \\
Parental impatience to children \\
Mation
\end{tabular}

\begin{tabular}{c}
\hline Unstandardized coef. \\
\hline 0.0001 \\
0.2748 \\
-0.0079 \\
-0.0528 \\
0.0444 \\
0.0500 \\
0.0208 \\
0.3973 \\
0.1366 \\
0.0493 \\
-0.1275 \\
0.0670 \\
-0.0990 \\
-0.0034 \\
-0.0273 \\
-0.0627 \\
0.0098 \\
-0.1190 \\
0.0055 \\
0.0089 \\
-0.0564 \\
0.0205 \\
-0.0287 \\
-0.0464 \\
\end{tabular}

\begin{tabular}{c}
\hline $\mathbf{9 5 \%} \mathbf{C l}$ \\
\hline-0.0022 to 0.0023 \\
0.2247 to 0.3248 \\
-0.0859 to 0.0702 \\
-0.0642 to -0.0415 \\
0.0390 to 0.0499 \\
0.0445 to 0.0551 \\
0.0101 to 0.0315 \\
0.3375 to 0.4572 \\
0.0414 to 0.2318 \\
-0.0386 to 0.1371 \\
-0.1907 to -0.0643 \\
-0.2844 to 0.4185 \\
-0.1523 to -0.0457 \\
-0.0625 to 0.0557 \\
-0.0535 to -0.0010 \\
-0.1097 to -0.0158 \\
-0.0098 to 0.0295 \\
-0.1706 to -0.0674 \\
-0.0051 to 0.0161 \\
0.0000 to 0.0178 \\
-0.1057 to -0.0071 \\
-0.0345 to 0.0756 \\
-0.0636 to 0.0063 \\
-0.0823 to -0.0104 \\
\hline
\end{tabular}

$\begin{array}{r}\multicolumn{1}{c}{\boldsymbol{P}} \\ \hline 0.948 \\ <0.001 \\ 0.843 \\ <0.001 \\ <0.001 \\ <0.001 \\ <0.001 \\ <0.001 \\ 0.005 \\ 0.272 \\ <0.001 \\ 0.708 \\ <0.001 \\ 0.909 \\ 0.042 \\ 0.009 \\ 0.325 \\ <0.001 \\ 0.306 \\ 0.049 \\ 0.025 \\ 0.465 \\ 0.108 \\ 0.012 \\ \hline\end{array}$

\begin{tabular}{c}
\hline Standardized coef. \\
\hline 0.0007 \\
0.1107 \\
-0.0030 \\
-0.0942 \\
0.1721 \\
0.2072 \\
0.0413 \\
0.1457 \\
0.0293 \\
0.0114 \\
-0.0507 \\
0.0038 \\
-0.0377 \\
-0.0012 \\
-0.0213 \\
-0.0273 \\
0.0102 \\
-0.0473 \\
0.0192 \\
0.0356 \\
-0.0370 \\
0.0122 \\
-0.0219 \\
-0.0266 \\
\end{tabular}

Coef, coefficient.

https://ec.bioscientifica.com

https://doi.org/10.1530/EC-21-0147 (c) 2021 The authors Published by Bioscientifica Ltd

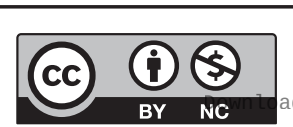

This work is licensed under a Creative Commons Attribution-NonCommercial 4.0 International License. ded from Bioscientifica.com at 04/26/2023 12:01:54PM via free access 


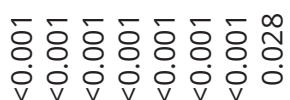

б.

जे $\dot{v} \vec{v} \dot{v} \vec{v}$

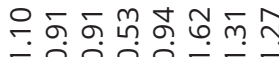

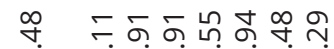

- 000000

$\begin{array}{ccccccc}0 & 0 & 0 & 0 & 0 & - & - \\ 0 & 0 & 0 & 0 & 0 & 0 & 0\end{array}$

นกㅇ

-ं000்-

엉 융드

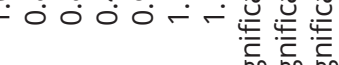

$\bar{n}$

$\frac{500}{n} \cdot \frac{50}{n} \cdot \frac{50}{n}$

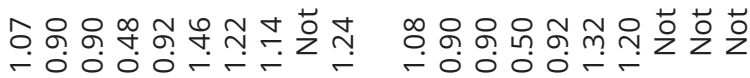

-0
0

(1)

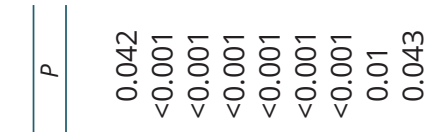

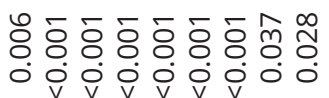

$\bar{\sigma} \bar{\delta} \bar{\delta} \bar{\delta} \bar{\delta} \overline{0} \delta \hat{m}$

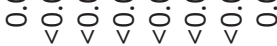

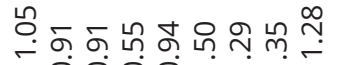

$\circ \begin{array}{llllll}0 & 0 & 0 & 0 & - & - \\ 0 & 0 & 0 & 0 & 0 & 0\end{array}$

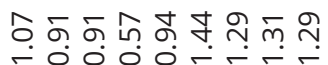

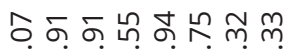

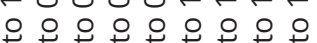

응

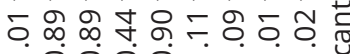

- $0000 \leftarrow \leftarrow \leftarrow$

$\leftarrow 0000 \div-\leftarrow$

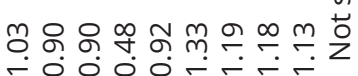

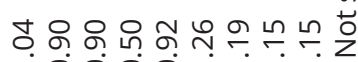

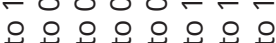

ธ $\infty$ ๙

- $0000 \leftarrow \leftarrow$ 论

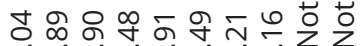

- $0000 \div-\div \bar{L}$

- $0000 \leftarrow \leftarrow$.

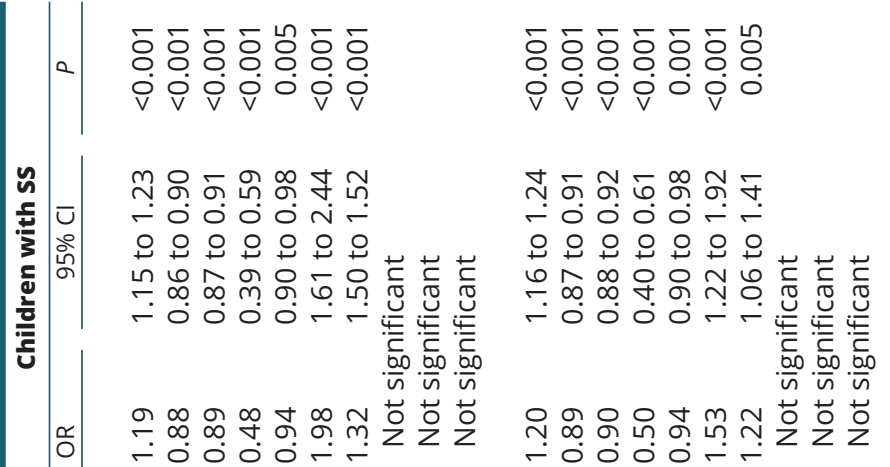

$\bar{\delta} \bar{\delta} \bar{\delta} \bar{\delta} \bar{\delta} \overline{0}$

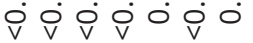

ฟัㅇำ ฝิ ลำ

-.0.0.

웅ㅇㅇㅇㅇㅛ

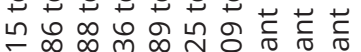

$\because 000 \%$

กุ Z Z Z

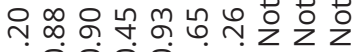

- 0 0.

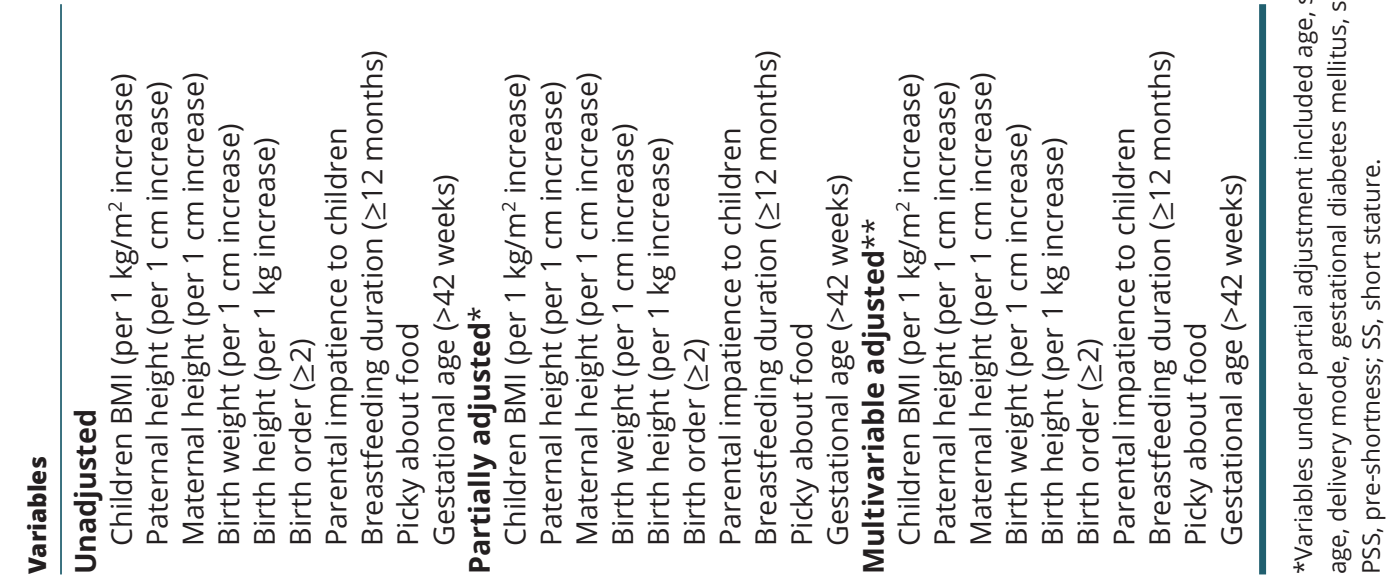


Next, Logistic regression analyses were performed with all the significant possible factors identified by multivariable linear regression analyses at a significant level of $5 \%$. Adjusting for confounders was implemented in a step-bystep manner: (i) without adjustment, (ii) partial adjustment for age, sex, and region, and (iii) multivariable adjustment additionally for time spent on outdoor activities every day, twins, gestational age, delivery mode, gestational diabetes mellitus, solid food introduction age, parental age at delivery, parental education, and family income. Effect-size estimates were expressed as odds ratio (OR) and 95\% CI.

Prediction accuracy of significant factors was appraised from both calibration and discrimination aspects. Calibration statistics include Akaike information criterion (AIC), Bayesian information criterion (BIC), -2 log likelihood ratio test, as well as the Hosmer-Lemeshow test. Discrimination statistics include the area under the receiver operating characteristic (ROC) to justify the improvement in prediction performance. Additionally, the net benefit for adding significant factors was justified by decision curve analysis (23).

Finally, on the basis of significant factors for short stature, pre-shortness and both, prediction nomogram models were constructed, and these models were generated by the R language version 3.5.2 for Windows.

Unless otherwise reported, statistical analyses were completed using the STATA software version 14.0 (Stata Corp, TX) for the Windows. Two-sided $P$ value of less than $5 \%$ was accepted to be statistically significant. Statistical power was estimated using the PS Power and Sample Size Calculations software version 3.0.

\section{Results}

\section{Baseline characteristics}

Questionnaires were sent to the parents or guardians of 10,441 children initially, and $98 \%$ of them $(n=10230)$ returned the questionnaires within scheduled time. Completed questionnaires were strictly reviewed by trained staff, and finally, 9501 of them were deemed eligible for inclusion. The baseline characteristics of 9501 children in this study are shown in Table 1.

In this study, the prevalence of short stature and pre-shortness was $3.9 \%(n=375)$ and $13.1 \%(n=1616)$, respectively. In addition, the ICC statistic indicated no evidence of potential bias arising from different kindergartens $(P<0.01)$.

\section{Identification of contributing predictors}

As shown in Table 2, multivariable linear regression analyses showed that 15 factors were significantly associated with higher height S.D. Six of them were positive, including males, maternal height, paternal height, birth weight, birth height, and gestational age. Nine were negative, including children BMI, latter birth order $\geq 2$, breastfeeding duration $>12$ months, higher night meals and fast food intake frequency, picky eating, paternal age at delivery, maternal education, and less parental patience to children. All significant factors identified by multivariable linear regression analyses were subsequently incorporated into logistic regression analyses except for males, paternal age

Table 4 Prediction accuracy gained by adding the significant factors identified for short stature or pre-shortness in preschoolaged children.

\begin{tabular}{|c|c|c|c|c|c|c|}
\hline \multirow[b]{2}{*}{ Statistics } & \multicolumn{2}{|c|}{ Children with SS } & \multicolumn{2}{|c|}{ Children with PSS } & \multicolumn{2}{|c|}{ Children with SS or PSS } \\
\hline & Basic model & Full model & Basic model & Full model & Basic model & Full model \\
\hline \multicolumn{7}{|l|}{ Calibration } \\
\hline $\mathrm{AIC}$ & 2650.990 & 2274.083 & 6348.298 & 5603.153 & 7570.499 & 6598.163 \\
\hline $\mathrm{BIC}$ & 2775.393 & 2445.800 & 6474.433 & 5784.255 & 7697.360 & 6773.304 \\
\hline LR test $(\chi 2)$ & \multicolumn{2}{|c|}{283.94} & \multicolumn{2}{|c|}{511.88} & \multicolumn{2}{|c|}{684.80} \\
\hline LR test ( $P$ value) & \multicolumn{2}{|c|}{$<0.001$} & \multicolumn{2}{|c|}{$<0.001$} & \multicolumn{2}{|c|}{$<0.001$} \\
\hline HL test ( $P$ value) & 0.454 & 0.225 & 0.379 & 0.304 & 0.363 & 0.203 \\
\hline \multicolumn{7}{|l|}{ Discrimination } \\
\hline IDI ( $P$ value) & \multicolumn{2}{|c|}{$<0.001$} & \multirow{2}{*}{\multicolumn{2}{|c|}{$\begin{array}{l}<0.001 \\
<0.001\end{array}$}} & \multicolumn{2}{|c|}{$<0.001$} \\
\hline AUROC ( $P$ value) & \multicolumn{2}{|c|}{$<0.001$} & & & \multicolumn{2}{|c|}{$<0.001$} \\
\hline
\end{tabular}

Basic model included age, sex, region, night meals intake frequency, fast food intake frequency, time spent on outdoor activities every day, picky about food, twins, gestational age, delivery mode, gestational diabetes mellitus, solid food introduction age, parental age at delivery, parental education, family income; Full model additionally included parental height, maternal height, birth weight, birth height, BMI, birth orders ( $\geq 2$ ) and parental impatience to children for both short stature and short stature or pre-shortness, parental height, maternal height, birth weight, birth height, BMI, birth orders ( $\geq 2$ ), parental impatience to children and breastfeeding duration (>12 months) for pre-shortness.

AIC, Akaike information criterion; AUROC, area under the receiver operating characteristic; BIC, Bayesian information criterion; IDI, integrated discrimination improvement; LR, likelihood ratio; PSS, pre-shortness; SS, short stature.

https://ec.bioscientifica.com

https://doi.org/10.1530/EC-21-0147 (c) 2021 The authors Published by Bioscientifica Ltd

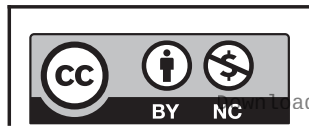

This work is licensed under a Creative Commons Attribution-NonCommercial 4.0 International License. ded from Bioscientifica.com at 04/26/2023 12:01:54PM 


\section{A Childhood SS}

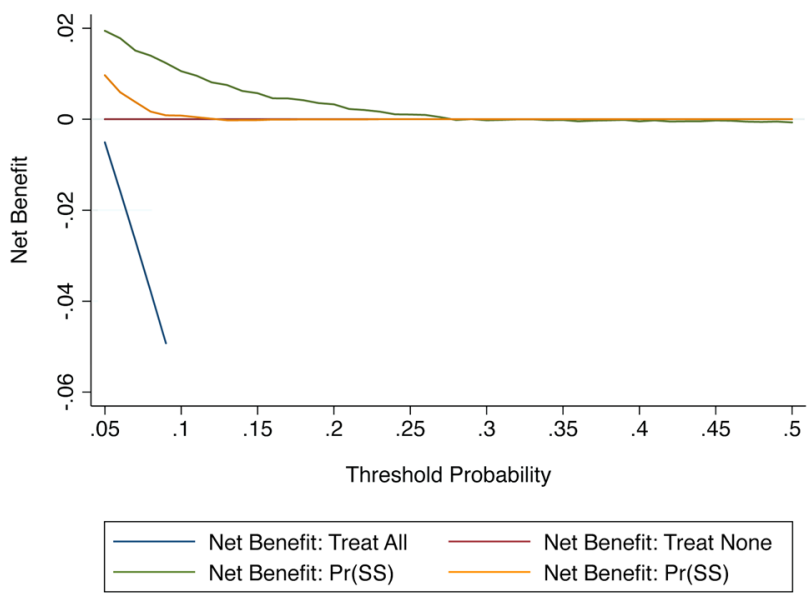

\section{B Childhood PSS}

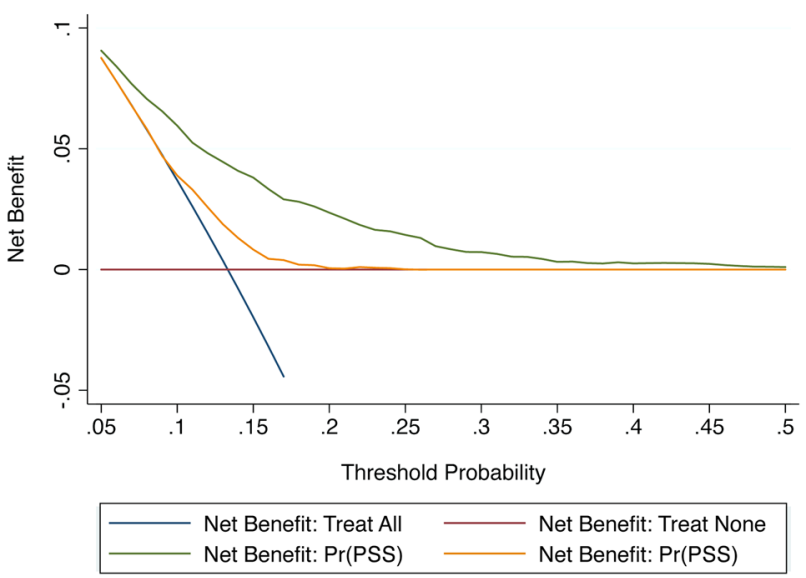

\section{Childhood SS or PSS}

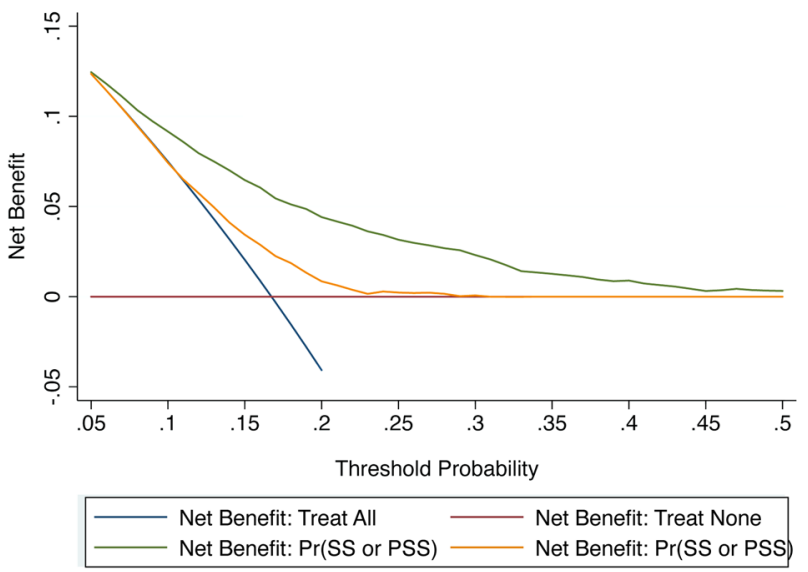

Figure 1

Decision curve analysis for SS, PSS and SS or PSS in preschool-aged children. SS, short stature; PSS, pre-shortness. at delivery and maternal education that were deemed as confounder factors under adjustment.

As shown in Table 3, after partial and multivariable adjustment, six contributing factors involving children BMI (OR, 95\% CI, $P$ for short stature: $1.20,1.15$ to 1.24 , $<0.001)$, paternal height $(0.88,0.86$ to $0.90,<0.001)$, maternal height $(0.90,0.88$ to $0.92,<0.001)$, birth weight $(0.45,0.36$ to $0.57,<0.001)$, birth height $(0.93,0.89$ to 0.97 , $0.001)$, latter birth order $(\geq 2)(1.65,1.25$ to $2.19,<0.001)$ and less parental patience to children (1.26, 1.09 to 1.46 , 0.002 ) were significantly associated with childhood short stature, pre-shortness and both. In addition, breastfeeding duration ( $>12$ months) (OR, 95\% CI, $P$ for pre-shortness: $1.16,1.01$ to $1.33,0.037)$ was significantly correlated to childhood pre-shortness.

\section{Prediction accuracy assessment}

The prediction accuracy of the identified factors for short stature, pre-shortness and both was assessed by comparing two models, viz. full model (all variables in the survey) and basic model (all variables except the significant factors), from both calibration and discrimination aspects (Table 4). Significant improvement was seen after adding the significant factors under each group classification. For example, as revealed by the $-2 \log$ likelihood ratio test, full model and basic model differed significantly in prediction performance under short stature, pre-shortness and both (all $P<0.0001$ ). Additionally, decision curve analysis indicated that the net benefits gained by adding the significant factors to the basic model were obvious (Fig. 1).

\section{Prediction of BMI for short stature and pre-shortness}

To further interrogate the risk prediction of BMI for childhood short stature, pre-shortness and both, the ordinal Logistic regression analyses were used after multivariable adjustment for confounding factors (Table 5). BMI was analyzed on both continuous and categorical scales. Per $1 \mathrm{~kg} / \mathrm{m}^{2}$ increase in BMI was associated with 19\% increased risk of short stature (OR, 95\% CI, P: 1.19, 1.15 to $1.23,<0.001), 3 \%$ increased risk of pre-shortness (1.03, 1.001 to $1.05,0.042$ ) and $7 \%$ increased risk of short stature or pre-shortness $(1.07,1.05$ to $1.10,<0.001)$.

Figure 2 displays the risk prediction of continuous children BMI for childhood short stature, pre-shortness and both under the restricted cubic spline regression analysis after adjusting for age, sex and region. The tendency between children BMI and the risk of childhood short
This work is licensed under a Creative Commons Attribution-NonCommercial 4.0 International License. ded from Bioscientifica.com at 04/26/2023 12:01:54PM via free access 
stature were significantly positive, while pre-shortness was not that significant.

When BMI was analyzed on a categorical scale, childhood obesity was significantly associated with short stature $(3.45,2.62$ to $4.54,<0.001)$ and short stature or preshortness $(1.37,1.15$ to $1.64,<0.001)$. Childhood overweight was significantly associated with short stature $(1.94,1.45$ to $2.61,<0.001)$. Neither childhood obesity nor overweight had a significant relation with pre-shortness individually.

\section{Prediction nomogram model}

Risk prediction nomogram models were constructed for short stature, pre-shortness and both in preschool-aged children on the basis of the identified significant predictors (Fig. 3). The predictive accuracy was good as shown in Supplementary Fig. 1 (see section on supplementary materials given at the end of this article), and the C-index were $77.0,70.1$ and $71.2 \%$ for short stature, pre-shortness and both, respectively (all $P<0.001$ ).

Taking the nomogram model for short stature as an example: assuming the BMI of a child is $20 \mathrm{~kg} / \mathrm{m}^{2}(50$ points), the height of father is $165 \mathrm{~cm}$ (85 points), the height of mother is $155 \mathrm{~cm}$ (55 points), with birthweight 3 $\mathrm{kg}$ ( 37.5 points), birth height $50 \mathrm{~cm}$ ( 2.5 points), birth order is 2 ( 15 points), and parental patience to the child is 1 point (15 points), the probability of short stature is estimated to be about $50 \%$.

\section{Discussion}

In this large-scale cross-sectional survey of 9501 Chinese preschool-aged children, we aimed to identify and characterize potential factors associated with short stature and pre-shortness. The key finding of this survey was that six factors including children BMI, paternal height, maternal height, birth weight, birth height, birth order and parental patience to children were significantly associated with childhood short stature, pre-shortness, and both. Additionally, breastfeeding duration was a significant predictor for childhood pre-shortness. Furthermore, childhood obesity and overweight were both significantly associated with short stature. To our knowledge, this is so far the first report that has examined the joint contribution of inherited characteristics, nutrition status from the uterus to childhood, and family psychological environment to short stature and pre-shortness in Chinese preschool-aged children.

It is estimated that approximately $80 \%$ of the variance in human height is determined by inherited factors (24, 25 ), with the remaining $20 \%$ of variance by environmental factors such as nutrition status and psychological stress (26). Among people affected by short stature, $37 \%$ have familial short stature, $27 \%$ have a constitutional growth delay, and $17 \%$ have both $(27,28,29)$, which indicates great inherited patterns of short stature. Our current study supported the claim that short stature and preshortness were significantly determined by parental height $(13,30,31)$. Undoubtedly, besides inherited factors, the development processes of short stature and pre-shortness are also affected by modifiable environmental factors such as nutrition status and family psychological factors. First, the typical pattern of linear growth faltering begins in utero and progresses through early childhood (32), as our study indicated that birth height and birth weight reflecting in utero nutrition status were the robust predictors of

Table 5 Prediction of BMI on both continuous and categorical scales for SS, PS and SS or PS by using the ordinal Logistic regression analyses.

\begin{tabular}{|c|c|c|c|c|c|c|c|c|c|}
\hline \multirow[b]{2}{*}{ Variables } & \multicolumn{3}{|c|}{ Children with SS } & \multicolumn{3}{|c|}{ Children with PSS } & \multicolumn{3}{|c|}{ Children with SS or PSS } \\
\hline & OR & $95 \% \mathrm{Cl}$ & $P$ & OR & $95 \% \mathrm{Cl}$ & $P$ & OR & $95 \% \mathrm{Cl}$ & $P$ \\
\hline $\begin{array}{c}\text { Childrens' BMI (per } \\
1 \mathrm{~kg} / \mathrm{m}^{2} \text { increase) }\end{array}$ & 1.19 & 1.15 to 1.23 & $<0.001$ & 1.03 & 1.00 to 1.05 & 0.042 & 1.07 & 1.05 to 1.10 & $<0.001$ \\
\hline \multicolumn{10}{|c|}{ Childrens' BMI category } \\
\hline $\begin{array}{l}\text { Childhood } \\
\text { obesity }\end{array}$ & 3.45 & 2.62 to 4.54 & $<0.001$ & Not significant & & & 1.37 & 1.15 to 1.64 & $<0.001$ \\
\hline $\begin{array}{l}\text { Childhood } \\
\text { overweight }\end{array}$ & 1.94 & 1.45 to 2.61 & $<0.001$ & Not significant & & & Not significant & & \\
\hline $\begin{array}{l}\text { Non overweight } \\
\text { or obesity }\end{array}$ & \multicolumn{3}{|c|}{ Reference } & Reference & & & Reference & & \\
\hline
\end{tabular}

$P$ values were calculated after adjusting for age, sex, region, night meals intake frequency, fast food intake frequency, time spent on outdoor activities every day, picky about food, twins, gestational age, delivery mode, gestational diabetes mellitus, solid food introduction age, parental age at delivery, parental education, family income.

PSS, pre-shortness; SS, short stature.

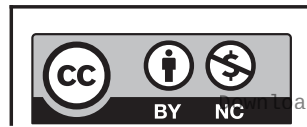

This work is licensed under a Creative Commons Attribution-NonCommercial 4.0 International License. ded from Bioscientifica.com at 04/26/2023 12:01:54PM via free access 


\section{A Childhood SS}

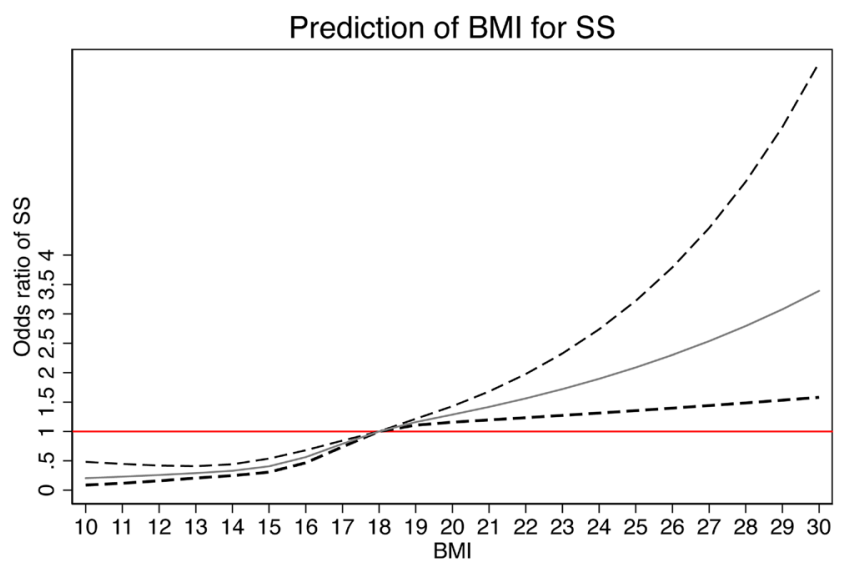

B Childhood PSS

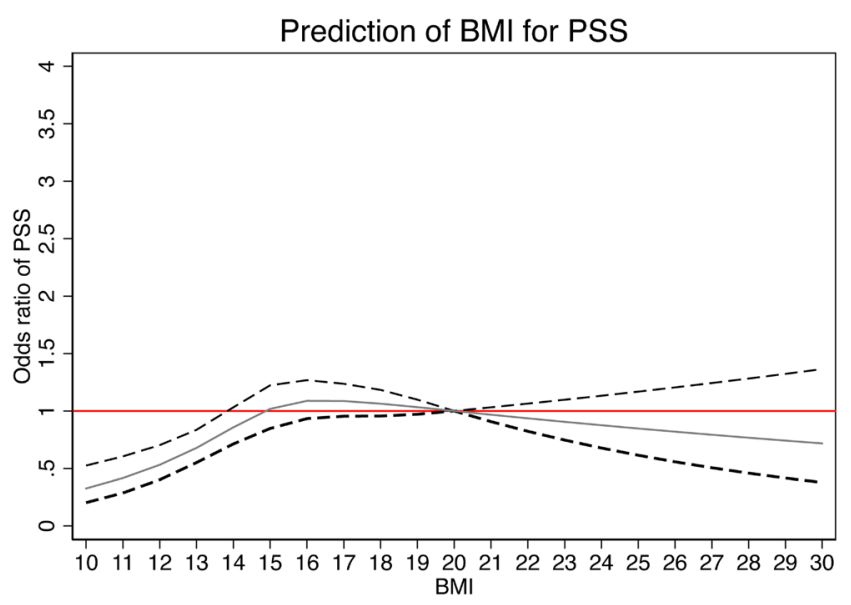

\section{Childhood SS or PSS}

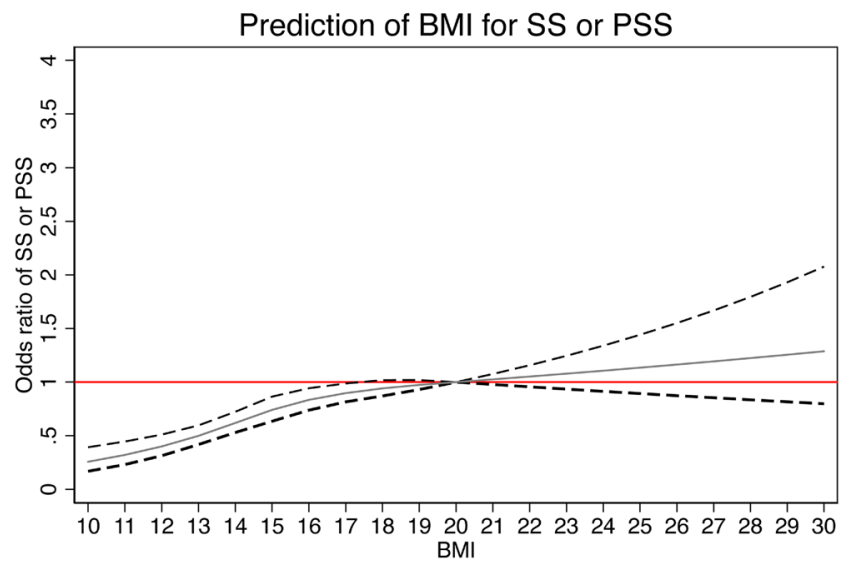

Figure 2

Risk of continuous BMI for SS, PSS, and SS or PSS among preschool children, after adjusting for age, sex and region. SS, short stature; PSS, pre-shortness. Lines with short dashes represent the $95 \% \mathrm{Cl}$. both short stature and pre-shortness, consistent with the findings of some previous studies $(33,34)$. Secondly, we found that children's higher BMI representing better nutrition status had a significantly positive association with short stature and pre-shortness, in agreement with that of most previous studies $(13,19)$. More importantly, our study reported for the first time that childhood obesity and overweight representing malnutrition status were significantly associated with short stature in preschoolaged children. Although some studies reported that obesity during adolenscence could enhance the precocious puberty and early epiphyseal closure accounting for short stature in adulthood (35); this still could not explain the relationship between obesity or overweight and short stature in the preschool period. We speculated that overweight or obesity representing malnutrition was in fact another form of unbalanced nutrition status which is harmful to linear growth. The precise underlying biological mechanisms need further exploration in future studies. Unfortunately, we failed to support that specifically low children BMI representing undernutrition was possitively associated with short stature and pre-shortness as a U-shape between BMI and risk of short stature or preshortness. It was possibly because of the very few numbers of children with very low BMI representing undernutrition owing to progressive socioeconomical conditions in Beijing and Tangshan, which caused the lack of statistical power. Therefore, we recommended that children should maintain normal BMI with a balanced nutrition status so as to avoid short stature or pre-shortness.

Several important findings distinguishing the present study merit adequate discussion. First, parental patience to children that could impact childhood psychological health was found to be inversely associated with the occurrence of short stature and pre-shortness. It is well known that parents with less patience are often in an unstable emotional status and irritable, which may create a long-term stressful family environment for children. There is an emerging notion that a stressful environment changes a child's gene expression and hormonal activity and contributes to biological changes that may lead to mental and physical disorders (36). The specific biological mechanisms of the impact of parental impatience on childhood short stature and pre-shortness worth further investigation. Secondly, birth order $\geq 2$ was for the first time found to be positively associated with the risk for childhood short stature and pre-shortness. The possible explanation was that latter birth order means larger family size and the association of short stature with large family size was confirmed $(37,38)$. It is hypothesized that children in the larger families are compatible with deprivation of
This work is licensed under a Creative Commons Attribution-NonCommercial 4.0 International License. ded from Bioscientifica.com at 04/26/2023 12:01:54PM 


\section{A Childhood SS}

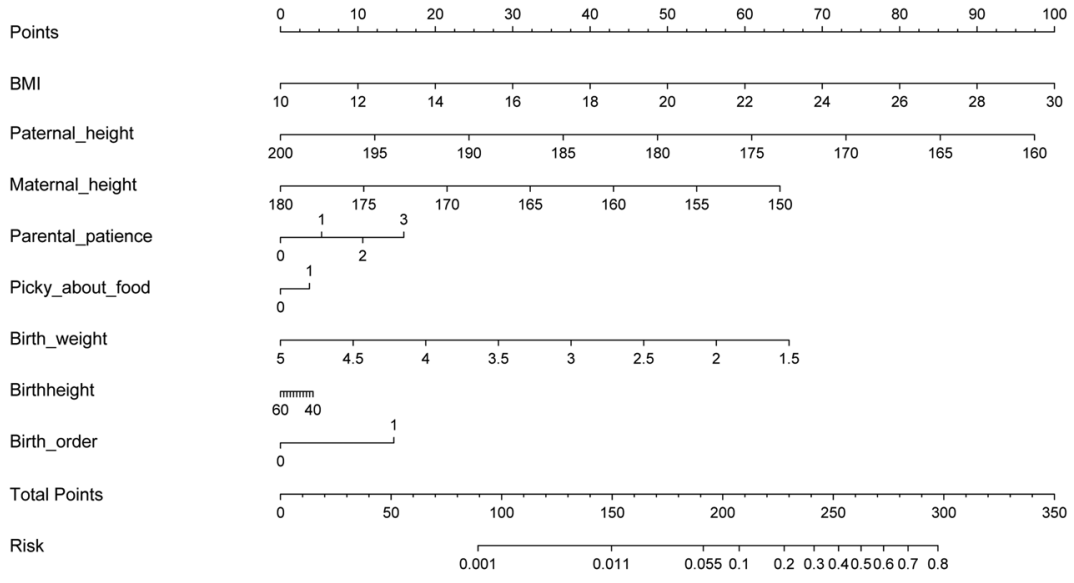

\section{B Childhood PSS}

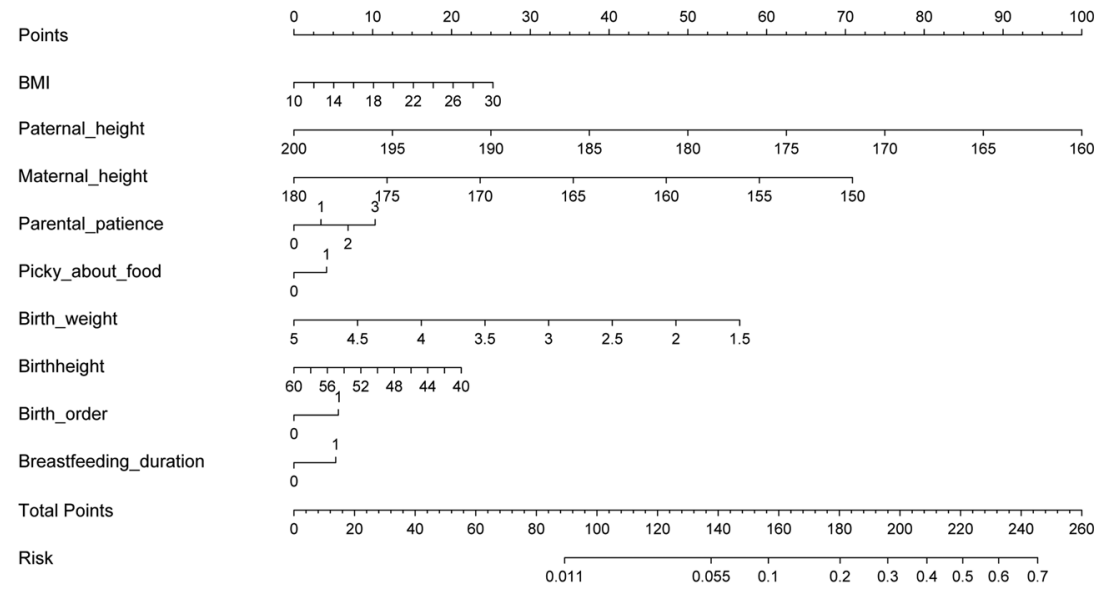

\section{Childhood SS or PSS}

Points

BMI

Paternal_height

Maternal_height

Parental_patience

Picky_about_food

Birth_weight

Birthheight

Birth order

Total Points

Risk

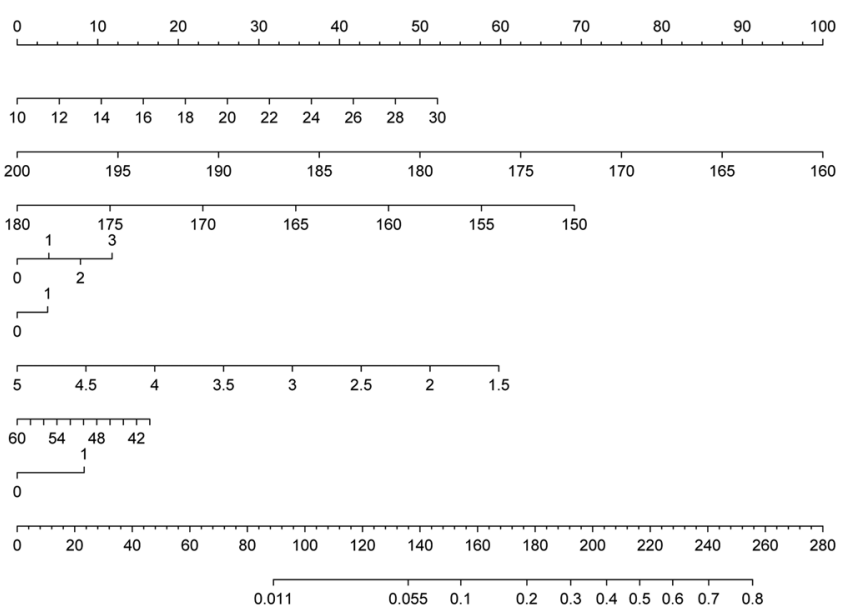

\section{Figure 3}

The prediction nomogram models for SS, PSS and SS or PSS in preschool-aged children. SS, short stature; PSS, pre-shortness. Lines with short dashes represent the $95 \% \mathrm{Cl}$. Here, ' 0 ' and ' 1 ' of 'Picky_eating' were defined as without picky eating and with picky eating. ' 0 ' and ' 1 ' of 'Birth_ order' represented $<2$ and $\geq 2$, respectively. ' 0 ' and ' 1 ' of 'Breastfeeding_duration' were defined as $<12$ months and $\geq 12$ months according to the mean value. ' 0 ', ' 1 ', ' 2 ', and ' 3 ' of 'Parental_ patience' represented parental self-rating patience to children separated into 10 points, 7-9 points, 4-6 points, and 1-3 points. https://ec.bioscientifica.com https://doi.org/10.1530/EC-21-0147 (c) 2021 The authors Published by Bioscientifica Ltd Attribution-NonCommercial 4.0 International License. ded from Bioscientifica.com at 04/26/2023 12:01:54PM via free access 
parental care and love, which may affect psychological development or relatively worse family income contributing to limited linear growth of children. Thirdly, we found that breastfeeding duration of more than 12 months was a significant risk factor for pre-shortness that is rarely reported in the literature. Most studies have reported a reduction in the risk of child undernutrition, with evidence for a dose-response relationship between breastfeeding duration and reduced risk $(39,40,41)$. However, according to our results and the recommendation of the World Health Organization (WHO) that breastfeeding duration should be more than 6 months (42), we recommend moderate breastfeeding duration between 6 and 12 months. Because human milk may become less nutritional along with changeable components over time (43), excessive long-term breastfeeding may cause undernutrition against the linear growth of children instead.

\section{Limitations}

Several possible limitations need to be acknowledged. First, this was a cross-sectional study, precluding further comments on the cause-effect relationship. Secondly, our data were obtained through questionnaires filled in by the parents or guardians of study children, and hence, recall bias cannot be excluded. Thirdly, although children with diagnosed chronic diseases causing pathological short stature were excluded at enrollment, those children not yet been diagnosed could not be excluded merely by the questionnaires.

\section{Conclusions}

In conclusion, our findings indicate that short stature and pre-shortness are determined by the joint contribution of multiple potential factors including inherited, nutritional, and psychological factors in Chinese pre-school children. It is helpful in making intervention strategies for preventing short stature or pre-shortness and improving height gain in early childhood. Further explorations are still necessary to clarify the underlying biological mechanisms of short stature or pre-shortness.

\section{Supplementary materials}

This is linked to the online version of the paper at https://doi.org/10.1530/ EC-21-0147.

\section{Declaration of interest}

The authors declare that there is no conflict of interest that could be perceived as prejudicing the impartiality of the research reported.

\section{Funding}

This work did not receive any specific grant from any funding agency in the public, commercial, or not-for-profit sector.

Data availability statement

Data and codes involved in this study are available upon reasonable request.

\section{Author contribution statement}

Z Z planned and designed the study and directed its implementation and drafted the protocol; $M Y, X D, B Z$, and S W obtained statutory and ethics approvals; $M Y$ and $B Z$ contributed to data acquisition; $M Y$ and W N conducted statistical analyses; M Y, X D, B Z and S W did the data preparation and quality control; $\mathrm{M} \mathrm{Y}$ and $\mathrm{W} \mathrm{N}$ wrote the manuscript. All authors read and approved the final manuscript prior to submission.

\section{Acknowledgements}

The authors are grateful to all participating children and their parents or guardians for their cooperation and willingness, as well as kindergarten teachers and health physicians for their great help.

\section{References}

1 Zayed AA, Beano AM, Haddadin FI, Radwan SS, Allauzy SA, Alkhayyat MM, Al-Dahabrah ZA, Al-Hasan YG \& Yousef AF. Prevalence of short stature, underweight, overweight, and obesity among school children in Jordan. BMC Public Health 201616 1040. (https://doi. org/10.1186/s12889-016-3687-4)

2 Velayutham K, Selvan SSA, Jeyabalaji RV \& Balaji S. Prevalence and etiological profile of short stature among school children in a South Indian population. Indian Journal of Endocrinology and Metabolism 2017 21 820-822. (https://doi.org/10.4103/ijem.IJEM_149_17)

3 Mendez N, Barrera-Pérez TL, Palma-Solis M, Zavala-Castro J, Dickinson F, Azcorra H \& Prelip M. Ethnicity and income impact on BMI and stature of school children living in urban southern mexico. Journal of Biosocial Science 201648 143-157. (https://doi.org/10.1017/ S0021932015000127)

4 Ma J, Pei T, Dong F, Dong Y, Yang Z, Chen J, Guo S, Zhao Q, Wang S, $\mathrm{Ma} J$ et al. Spatial and demographic disparities in short stature among school children aged 7-18 years: a nation-wide survey in China, 2014. BMJ Open 20199 e026634. (https://doi.org/10.1136/ bmjopen-2018-026634)

5 Thomsett MJ. The spectrum of clinical paediatric endocrinology: 28 years of referrals to an individual consultant. Journal of Paediatrics and Child Health 201046 304-309. (https://doi.org/10.1111/j.14401754.2010.01713.x)

6 Quitmann JH, Bullinger M, Sommer R, Rohenkohl AC \& Bernardino Da Silva NM. Associations between psychological problems and quality of life in pediatric short stature from patients' and parents' perspectives. PLOS ONE 201611 e0153953. (https://doi.org/10.1371/ journal.pone.0153953)

7 Oh NK, Song YM, Kim SH \& Park MJ. Short stature is associated with increased risk of dyslipidemia in korean adolescents and adults. Scientific Reports 20199 14090. (https://doi.org/10.1038/s41598-019-50524-2)

8 Vangipurapu J, Stancáková A, Jauhiainen R, Kuusisto J \& Laakso M. Short adult stature predicts impaired $\beta$-cell function, insulin resistance, glycemia, and type 2 diabetes in finnish men. Journal of Clinical Endocrinology and Metabolism 2017102 443-450. (https://doi. org/10.1210/jc.2016-2933)

9 Yuan Y, Zhou B, Wang S, Ma J, Dong F, Yang M, Zhang Z \& Niu W. Adult body height and cardiometabolic disease risk: the China https://ec.bioscientifica.com

https://doi.org/10.1530/EC-21-0147 (c) 2021 The authors Published by Bioscientifica Ltd
This work is licensed under a Creative Commons Attribution-NonCommercial 4.0 International License. ded from Bioscientifica.com at 04/26/2023 12:01:54PM 
national health survey in Shaanxi. Frontiers in Endocrinology 202011 587616. (https://doi.org/10.3389/fendo.2020.587616)

10 Power C, Manor O \& Li L. Are inequalities in height underestimated by adult social position? Effects of changing social structure and height selection in a cohort study. BMJ 2002325 131-134. (https://doi. org/10.1136/bmj.325.7356.131)

11 Batty GD, Shipley MJ, Gunnell D, Huxley R, Kivimaki M, Woodward M, Lee CM \& Smith GD. Height, wealth, and health: an overview with new data from three longitudinal studies. Economics and Human Biology 20097 137-152. (https://doi.org/10.1016/j.ehb.2009.06.004)

12 Barker DJ, Eriksson JG, Forsén T \& Osmond C. Infant growth and income 50 years later. Archives of Disease in Childhood 200590 272-273. (https://doi.org/10.1136/adc.2003.033464)

13 Yuan Y, Zhou B, Wang K, Wang Y, Zhang Z \& Niu W. Identification of contributing predictors for short stature and pre-shortness among 7310 chinese preschool-aged children. Endocrine 202171 443-452. (https://doi.org/10.1007/s12020-020-02528-6)

14 Jelenkovic A, Sund R, Yokoyama Y, Latvala A, Sugawara M, Tanaka M, Matsumoto S, Freitas DL, Maia JA, Knafo-Noam A, et al. Genetic and environmental influences on human height from infancy through adulthood at different levels of parental education. Scientific Reports 202010 7974. (https://doi.org/10.1038/s41598-020-64883-8).

15 Jelenkovic A, Hur YM, Sund R, Yokoyama Y, Siribaddana SH, Hotopf M, Sumathipala A, Rijsdijk F, Tan Q, Zhang D, et al. Genetic and environmental influences on adult human height across birth cohorts from 1886 to 1994. eLife 2016 5. (https://doi.org/10.7554/eLife.20320)

16 Casaña-Granell S, Lacomba-Trejo L, Montoya-Castilla I \& Pérez-Marín M. Adolescence and short stature: factors in adjustment to the diagnosis. Quality of Life Research 2021. (https://doi.org/10.1007/s11136-021-02798-1)

17 Liu X, Du Z, Yi X, Sheng T, Yuan J \& Jia J. Circular RNA circANAPC2 mediates the impairment of endochondral ossification by miR-874-3p/ SMAD3 signalling pathway in idiopathic short stature. Journal of Cellular and Molecular Medicine 202125 3408-3426. (https://doi. org/10.1111/jcmm.16419)

18 Yu TT, Xu QF, Li SY, Huang HJ, Dugan S, Shao L, Roggenbuck JA, Liu XT, Liu HZ, Hirsch BA, et al. Deletion at an 1q24 locus reveals a critical role of long noncoding RNA DNM3OS in skeletal development. Cell and Bioscience 202111 47. (https://doi.org/10.1186/s13578-021-00559-8)

19 Holmgren A, Niklasson A, Nierop AF, Gelander L, Aronson AS, Sjöberg A, Lissner L \& Albertsson-Wikland K. Pubertal height gain is inversely related to peak BMI in childhood. Pediatric Research $2017 \mathbf{8 1}$ 448-454. (https://doi.org/10.1038/pr.2016.253)

20 Geva N, Pinhas-Hamiel O, Reichman B, Derazne E, Vivante A, Barak Y, Afek A, Tirosh A \& Twig G. The association between obesity and secular trend of stature: a nationwide study of 2.8 million adolescents over five decades. International Journal of Obesity 201943 1932-1939. (https://doi.org/10.1038/s41366-019-0371-7)

$21 \mathrm{Li} \mathrm{H}$, Ji CY, Zong XN \& Zhang YQ. Height and weight standardized growth charts for Chinese children and adolescents aged 0 to 18 years. Zhong hua Er Ke Za Zhi 200947 487-492.

$22 \mathrm{Li} \mathrm{H}$, Ji CY, Zong XN \& Zhang YQ. Body mass index growth curves for Chinese children and adolescents aged 0 to 18 years. Zhong hua Er Ke Za Zhi 200947 493-498.

23 Vickers AJ \& Elkin EB. Decision curve analysis: a novel method for evaluating prediction models. Medical Decision Making 200626 565-574. (https://doi.org/10.1177/0272989X06295361)

24 Lanktree MB, Guo Y, Murtaza M, Glessner JT, Bailey SD, OnlandMoret NC, Lettre G, Ongen H, Rajagopalan R, Johnson T, et al. Metaanalysis of dense Genecentric association studies reveals common and uncommon variants associated with height. American Journal of Human Genetics 201188 6-18. (https://doi.org/10.1016/j.ajhg.2010.11.007)

25 Grunauer M \& Jorge AAL. Genetic short stature. Growth Hormone and IGF Research 201838 29-33. (https://doi.org/10.1016/j.ghir.2017.12.003)
26 Silventoinen K. Determinants of variation in adult body height. Journal of Biosocial Science 200335 263-285. (https://doi.org/10.1017/ s0021932003002633)

27 Lindsay R, Feldkamp M, Harris D, Robertson J \& Rallison M. Utah Growth Study: growth standards and the prevalence of growth hormone deficiency. Journal of Pediatrics 1994125 29-35. (https://doi. org/10.1016/s0022-3476(94)70117-2)

28 Moore KC, Donaldson DL, Ideus PL, Gifford RA \& Moore WV. Clinical diagnoses of children with extremely short stature and their response to growth hormone. Journal of Pediatrics 1993122 687-692. (https:// doi.org/10.1016/s0022-3476(06)80005-3)

29 Sisley S, Trujillo MV, Khoury J \& Backeljauw P. Low incidence of pathology detection and high cost of screening in the evaluation of asymptomatic short children. Journal of Pediatrics 2013163 1045-1051. (https://doi.org/10.1016/j.jpeds.2013.04.002)

30 Cole TJ \& Wright CM. A chart to predict adult height from a child's current height. Annals of Human Biology 201138 662-668. (https://doi. org/10.3109/03014460.2011.598189).

31 Lin YJ, Liao WL, Wang CH, Tsai LP, Tang CH, Chen CH, Wu JY, Liang WM, Hsieh AR, Cheng CF, et al. Association of human height-related genetic variants with familial short stature in Han Chinese in Taiwan. Scientific Reports 2017 7. (https://doi.org/10.1038/s41598-017-06766-z)

32 Victora CG, de Onis M, Hallal PC, Blössner M \& Shrimpton R. Worldwide timing of growth faltering: revisiting implications for interventions. Pediatrics 2010125 e473-e480. (https://doi.org/10.1542/peds.2009-1519).

33 Jahanfar S. Birth weight and anthropometric measurements of twins. Annals of Human Biology 201845 395-400. (https://doi.org/10.1080/03 014460.2018.1526320)

34 Davallow Ghajar L \& DeBoer MD. Environmental and birth characteristics as predictors of short stature in early childhood. Acta Paediatrica 2019108 954-960. (https://doi.org/10.1111/apa.14617)

35 Fan HY, Lee YL, Hsieh RH, Yang C \& Chen YC. Body mass index growth trajectories, early pubertal maturation, and short stature. Pediatric Research 202088 117-124. (https://doi.org/10.1038/s41390019-0690-3)

36 Romens SE, McDonald J, Svaren J \& Pollak SD. Associations between early life stress and gene methylation in children. Child Development 201586 303-309. (https://doi.org/10.1111/cdev.12270)

37 Moyes CD. Stature and birth rank. A study of schoolchildren in St Helena. Archives of Disease in Childhood 198156 116-120. (https://doi. org/10.1136/adc.56.2.116)

38 Campos AP, Vilar-Compte M \& Hawkins SS. Association Between breastfeeding and child stunting in Mexico. Annals of Global Health 202086 145. (https://doi.org/10.5334/aogh.2836)

39 Danaei G, Andrews KG, Sudfeld CR, Fink G, McCoy DC, Peet E, Sania A, Smith Fawzi MC, Ezzati M \& Fawzi WW. Risk factors for childhood stunting in 137 developing countries: a comparative risk assessment analysis at global, regional, and country levels. PLoS Medicine 201613 e1002164. (https://doi.org/10.1371/journal.pmed.1002164)

40 Cruz LMG, Azpeitia GG, Súarez DR, Rodríguez AS, Ferrer JFL \& SerraMajem L. Factors associated with stunting among children aged 0 to 59 months from the central region of mozambique. Nutrients 20179. (https://doi.org/10.3390/nu9050491)

41 Khan MN \& Islam MM. Effect of exclusive breastfeeding on selected adverse health and nutritional outcomes: a nationally representative study. BMC Public Health 201717 889. (https://doi.org/10.1186/ s12889-017-4913-4)

42 Organization WHO. The Optimal Duration of Exclusive Breastfeeding: Report of an Expert Consultation. Geneva: World Health Organization, 2001.

43 Mosca F \& Giannì ML. Human milk: composition and health benefits. Pediatria Medica e Chirurgica: Medical and Surgical Pediatrics 201739 155. (https://doi.org/10.4081/pmc.2017.155)

Received in final form 12 May 2021

Accepted 19 May 2021

Accepted Manuscript published online 19 May 2021 https://ec.bioscientifica.com https://doi.org/10.1530/EC-21-0147
This work is licensed under a Creative Commons Attribution-NonCommercial 4.0 International License. ded from Bioscientifica.com at 04/26/2023 12:01:54PM 